\title{
CO-RADS versus CT-SS scores in predicting severe COVID-19 patients: retrospective comparative study
}

\author{
Niveen E. Zayed ${ }^{1 *}$, Manar A. Bessar ${ }^{2}$ and Samah Lutfy ${ }^{1}$
}

\begin{abstract}
Background: The role of $\mathrm{CT}$ in assessing and plotting viral pulmonary affection land marking is its potential among other investigation tools, and the aim of the study was to compare the ability of two different CT-based scoring systems in discriminating severe COVID-19 disease.

Results: Retrospective comparative study included 142 confirmed COVID-19 patients by real-time polymerase chain reaction (RT-PCR) test, with different degrees of disease (mild to severe), the data of patients collected from medical records, and patients with their first CT chest read for calculating CO-RADS and severity scoring system (CT-SS) score. The patients with severe COVID-19 disease were significantly older and had different comorbidities. The level of $C$-reactive protein, ESR, ferritin, and LDH were significantly higher in severe disease, $P<0.001$. The ability of CT chest and its score bases (CT-SS and CO-RADS) were accurate in differentiation between mild/moderate and severe disease; AUC were $89 \%$ and 97\%, respectively. The cutoff value of less than 7.5 and 4.5 for CT-SS and CO-RADS, respectively, can rule out severe COVID-19 by $90 \%$ and $97 \%$, respectively.
\end{abstract}

Conclusions: $C T$ chest play a segregate role in COVID-19 disease, add on an advantage in clinical data in triage, and highlight the decision of hospital admission.

Keywords: Chest CT, CT-SS, CO-RADS, COVID-19

\section{Background}

In December 2019, a pneumonia outbreak was reported by the International Committee on Taxonomy of Viruses in China as a result of a new zoonotic virus; the novel virus was named severe respiratory distress syndrome corona virus 2 (SARS-Cov-2) and can spread from human to another [1]. The WHO declared the disease as a pandemic disease by January 2020. The disease spread fast and globally; therefore, the need for rapid and accurate methods for early recognition and diagnosis of affected patients was increased [2].

The clinical features of SARS-Cov-2 infection and its preceding beta corona virus infections have been noted, and hence, most patients presented with influenza-like

\footnotetext{
* Correspondence: niveenzayed@yahoo.com

${ }^{1}$ Chest Department, Faculty of Medicine, Zagazig University, Zagazig, Egypt Full list of author information is available at the end of the article
}

symptoms as fever, cough, and fatigue [3]. The disease may deteriorate causing severe respiratory distress syndrome as a consequence of pneumonia [4].

The gold standard method for diagnosing SARS-Cov-2 virus infection is real-time reverse transcriptase polymerase chain reaction (RT RT-PCT) or next-generation sequencing [3]. However, the sensitivity of these tests ranged from 42 to $83 \%$ depending on many factors like viral load, test sample quality, and duration of symptoms [5-9]. Moreover, the test did not impose the severity of the disease or its consequence [6]. Accordingly, another investigation side-by-side to clinical data will give good severity stratification and stage classification of patients.

Radiological evaluation of patients with SARS-Cov-2 infection particularly by chest computed tomography (CT) has a reported high sensitivity and enhances the clinical decision that is based on the degree of lung
Springer Open

(c) The Author(s). 2021 Open Access This article is licensed under a Creative Commons Attribution 4.0 International License, which permits use, sharing, adaptation, distribution and reproduction in any medium or format, as long as you give appropriate credit to the original author(s) and the source, provide a link to the Creative Commons licence, and indicate if changes were made. The images or other third party material in this article are included in the article's Creative Commons licence, unless indicated otherwise in a credit line to the material. If material is not included in the article's Creative Commons licence and your intended use is not permitted by statutory regulation or exceeds the permitted use, you will need to obtain permission directly from the copyright holder. To view a copy of this licence, visit http://creativecommons.org/licenses/by/4.0/. 
affection [6, 10]. Yang and his colleagues [11] introduce a severity scoring system (CT-SS) that depends on the degree of lung affection in chest CT and is recommended to be used for quick assessment of pulmonary affection. Moreover, in March 2020, the Dutch Radiological Society developed another score system based on chest CT and patient's data; the COVID-19 Reporting and Data System (CO-RADS) included data of clinical finding and laboratory test results in addition to $\mathrm{CT}$ records [12]. The degree of suspicion ranged from very low to very high (CO-RADS categories $1-5)$, while category 0 reflects negative infection and category 6 establishes RT-PCR-positive SARS-Cov-2 infection at time of examination [12].

The current work is designed for enlightening the diagnostic utility of CT-SS in comparison with CORADS for evaluating patients with severe COVID-19.

\section{Methods}

\section{Study design and patient grouping}

A single-center retrospective comparative study included all RT-PCR positive cases for SARS-Cov-2 from the March 2020 to the end of June 2020 admitted in Saudi National Hospital. The study was approved by the Ethics Committee of Saudi National Hospital. A written informed consent was obtained from all participants

\section{Exclusion criteria}

The study includes all patients referred to the hospital who were proved to have COVID-19 by RT-PCR throat swab. Pregnant women were excluded due to risk of CT, and also, patients with tuberculosis, interstitial lung diseases, and pulmonary malignancy were excluded to avoid interference with radiological presentation of COVID-19.

The positive PCR COVID-19 cases classified with regard to the level of disease severity: Mild disease $(n=$ 22 ) included all cases with clinical symptoms and no changes in CT chest. Moderate cases $(n=62)$ involved all cases with respiratory symptoms with changes in CT. Severe cases $(n=17)$ defined by the presence of the following criteria: (1) respiratory distress, $R R \geq 30$ beats/ min, (2) resting blood oxygen saturation $\leq 93 \%$, or (3) partial pressure of arterial blood oxygen $(\mathrm{PaO} 2) /$ fraction of inspired oxygen (FiO2) concentration $\leq 300 \mathrm{mmHg}$. Critical ill cases $(n=41)$ included all severe cases that were deteriorating due to (1) respiratory failure and need of mechanical ventilation, (2) shock, and (3) other organ failure needing ICU monitoring treatment [13].

For the purposes of this study, mild and moderate cases were included in the same category $(n=84)$, while severe and critically ill cases were merged together $(n=58)$

\section{Clinical workflow and disease evaluation}

The data was collected from medical records and included demographic characteristic, clinical presentation, and routine laboratory investigation as $\mathrm{CBC}$ with lymphocytic count, C-reactive protein (CRP), erythrocyte sedimentation rate (ESR), D-dimer, lactate dehydrogenase (LDH), and arterial blood gas (ABG). In addition, the follow-up data included duration until conversion from positive to negative swab for SARS-Cov-2, length of stay in hospital, and mortality.

\section{Radiological work up}

a. Chest X-ray

The report of chest X-ray includes the site of lesion, presence of reticular, nodular, or opacity pattern.

\section{b. CT protocol and reading}

No specific protocol for CT imaging was applied; the study was retrospective, and two different multidetector CT scanners (Somatom Sensation 16 and Somatom Sensation 64; Siemens Healthineers) were used for all examinations as regards the manufacturer's standard recommended for scanning parameters used in thoracic radiology. All images were reconstructed on workstation using multiplanar reformatting (MPR) technique. Two different radiologists, blinded to the patient's clinical data, did the reading of each CT film; the least experience time on radiology filed for each collaborator was 10 years.

\section{Chest CT severity score assessment}

Yang and his colleagues [11] developed a scoring system (CT-SS) that depended on opacification degree in the lung. The score was a modern adaptation of a previous method that was used in patients with SARS-Cov-1 [14].

Regarding the lung anatomical structures, all 18 lung segments were subdivided into 20 regions, which were then evaluated subjectively using scoring grades from 0 to 2; hence, 0 refereed to no involvement, while 1 and 2 represent less than and more than $50 \%$ involvement, respectively. The summation of individual's scores of 20 regions pointed to total CT-SS score, which ranged from 0 to 40 points. The radiological terms that were established in use according to the Fleischner Society [15] includes ground glass opacity (GGO), crazy paving pattern, and pulmonary consolidation.

\section{CO-RADS score evaluation}

The radiologist who observed the patient's CT were familiar with CO-RADS score [12] from clinical experience on reading more than $45 \mathrm{CT}$ chest; they used a drop list option tools in recording the points irrespective of the data from the recruited patients in the study 
Table 1 Demographic data of COVID-19 patients

\begin{tabular}{|c|c|c|c|c|c|}
\hline \multirow{2}{*}{$\begin{array}{l}\text { Factors } \\
\text { Demographic characteristics }\end{array}$} & \multicolumn{2}{|c|}{ Mild/moderate $(n=84)$} & \multicolumn{2}{|c|}{ Severe/critically ill $(n=58)$} & \multirow[t]{2}{*}{$P$} \\
\hline & Mean/N & $\mathrm{SD} / \%$ & Mean/N & SD/\% & \\
\hline Age & 35.4 & 9.71 & 47.4 & 10.6 & $<0.001^{\mathrm{s}}$ \\
\hline Sex (male) & 70 & 83.33 & 46 & 79.31 & 0.61 \\
\hline Smoking (yes) & 22 & 26.19 & 19 & 32.76 & 0.47 \\
\hline \multicolumn{6}{|l|}{ Comorbidity (yes) } \\
\hline DM & 4 & 4.76 & 20 & 34.48 & $<0.001^{\#}$ \\
\hline HTN & 8 & 9.52 & 20 & 34.48 & $0.003^{\#}$ \\
\hline $\mathrm{HD}$ & 0 & 0 & 8 & 13.79 & $0.01^{\#}$ \\
\hline Asthma & 4 & 4.76 & 8 & 13.79 & 0.12 \\
\hline COPD & 0 & 0 & 2 & 3.45 & 0.51 \\
\hline Hyperlipidemia & 4 & 4.76 & 2 & 3.45 & 0.74 \\
\hline \multicolumn{6}{|l|}{ Clinical characteristic } \\
\hline Exposure history (yes) & 28 & 33.33 & 17 & 29.31 & 0.66 \\
\hline Duration from exposure till admission (days) & 9.14 & 1.96 & 9.18 & 1.98 & 0.96 \\
\hline Duration before admission (days) & 3.67 & 1 & 4.38 & 1.61 & $0.008^{\S}$ \\
\hline \multicolumn{6}{|l|}{ Symptoms (yes) } \\
\hline Fever & 76 & 90.48 & 52 & 89.66 & 0.89 \\
\hline Cough & 64 & 76.19 & 54 & 93.1 & $0.01^{\#}$ \\
\hline Expectoration & 8 & 9.52 & 4 & 6.9 & 0.63 \\
\hline Dyspnea & 12 & 14.29 & 38 & 65.52 & $<0.001^{\#}$ \\
\hline Myalgia & 32 & 38.1 & 34 & 58.62 & $0.04^{\#}$ \\
\hline Sore throat & 28 & 33.33 & 21 & 36.21 & 0.76 \\
\hline Hemoptysis & 0 & 0 & 5 & 8.62 & 0.051 \\
\hline Diarrhea & 20 & 23.81 & 38 & 65.52 & $<0.001^{\#}$ \\
\hline Loss of smell & 22 & 26.19 & 21 & 36.21 & 0.28 \\
\hline Anorexia & 20 & 23.81 & 14 & 24.14 & 0.97 \\
\hline \multicolumn{6}{|l|}{ Lab data } \\
\hline $\operatorname{TLC}\left(10^{9} / \mathrm{L}\right)$ & 5.89 & 1.99 & 6.24 & 2.43 & 0.42 \\
\hline $\mathrm{HB}(\mathrm{g} / \mathrm{dL})$ & 15.36 & 1.52 & 15.03 & 2.01 & 0.35 \\
\hline $\operatorname{PLT}\left(10^{9} / \mathrm{L}\right)$ & 194.1 & 53 & 198.5 & 71.2 & 0.72 \\
\hline MPV (pg/L) & 10.26 & 2 & 11.53 & 1.65 & $0.001^{\S}$ \\
\hline L (\%) & 27.08 & 7.51 & 19.92 & 7.26 & $<0.001^{\S}$ \\
\hline ESR $(\mathrm{mm} / \mathrm{h})$ & 31.7 & 18.4 & 49.5 & 19.3 & $<0.001^{\S}$ \\
\hline CRP (mg/L) & 39.5 & 23 & 93.4 & 50.3 & $<0.001^{\S}$ \\
\hline Ferritin (ng/mL) & 297 & 171 & 738 & 426 & $<0.001^{s}$ \\
\hline $\mathrm{LDH}(\mathrm{U} / \mathrm{L})$ & 340 & 154 & 496 & 234 & $<0.001^{\mathrm{s}}$ \\
\hline AST (U/L) & 44.2 & 20.3 & 61.6 & 31.3 & $0.001^{\S}$ \\
\hline $\mathrm{ALT}(\mathrm{U} / \mathrm{L})$ & 40 & 10.5 & 56.9 & 30.8 & $<0.001^{\S}$ \\
\hline Creatine (mg/dL) & 0.75 & 0.144 & 0.924 & 0.228 & $<0.001^{\S}$ \\
\hline D-dimer (positive) & 0 & 0 & 34 & 58.62 & $<0.001^{\#}$ \\
\hline CPK-MB (IU/L) & 14.07 & 3.58 & 20 & 5.71 & $<0.001^{\S}$ \\
\hline $\mathrm{PO} 2(\mathrm{mmHg})$ & 77.98 & 6.22 & 59.93 & 7.91 & $<0.001^{s}$ \\
\hline PCO2 (mmHg) & 38.95 & 2.32 & 34.77 & 4.03 & $<0.001^{\S}$ \\
\hline $\mathrm{PH}$ & 7.39 & 0.02 & 7.36 & 0.40 & 0.58 \\
\hline
\end{tabular}


Table 1 Demographic data of COVID-19 patients (Continued)

\begin{tabular}{|c|c|c|c|c|c|}
\hline \multirow{2}{*}{$\begin{array}{l}\text { Factors } \\
\text { Demographic characteristics }\end{array}$} & \multicolumn{2}{|c|}{ Mild/moderate $(n=84)$} & \multicolumn{2}{|c|}{ Severe/critically ill $(n=58)$} & \multirow[t]{2}{*}{$P$} \\
\hline & Mean/N & $\mathrm{SD} / \%$ & Mean/N & $\mathrm{SD} / \%$ & \\
\hline $\mathrm{HCO} 3(\mathrm{mEq} / \mathrm{L})$ & 21.31 & 1.72 & 20.46 & 2.4 & $0.04^{\S}$ \\
\hline $\mathrm{K}(\mathrm{mmol} / \mathrm{L})$ & 3.536 & 0.413 & 3.367 & 0.5 & 0.06 \\
\hline $\mathrm{Na}(\mathrm{mEq} / \mathrm{L})$ & 132.14 & 4.18 & 131.09 & 4.88 & 0.24 \\
\hline CO-RAD & 2.33 & 1.18 & 4.86 & 0.39 & $<0.001^{\S}$ \\
\hline
\end{tabular}

${ }^{5}$ Independent $t$ test

${ }^{\#}$ Chi-square test, $P$ considered significant if $P<0.05$

Continuous data represented as mean and standard deviation (SD), and categorical data as number and percentage (\%)

Table 2 Radiological characteristic of COVID-19 patients

\begin{tabular}{|c|c|c|c|c|c|}
\hline \multirow[t]{2}{*}{ Factors } & \multicolumn{2}{|c|}{ Mild/moderate $(n=84)$} & \multicolumn{2}{|c|}{ Severe/critically ill $(n=58)$} & \multirow[t]{2}{*}{$P$} \\
\hline & $\mathrm{N}$ & $\%$ & $\mathrm{~N}$ & $\%$ & \\
\hline X-ray abnormality & 36 & 42.86 & 58 & 100 & $<0.001^{\#}$ \\
\hline \multicolumn{6}{|l|}{ Side } \\
\hline Unilateral & 30 & 35.71 & 7 & 12.07 & $<0.001^{\#}$ \\
\hline Bilateral & 6 & 7.14 & 51 & 87.93 & $<0.001^{\#}$ \\
\hline Reticular shadow & 26 & 30.95 & 30 & 51.72 & $0.03^{\#}$ \\
\hline Opacity & 6 & 7.14 & 25 & 43.1 & $<0.001^{\#}$ \\
\hline Nodules & 2 & 2.38 & 5 & 8.62 & 0.19 \\
\hline \multicolumn{6}{|l|}{ CT changes } \\
\hline Anterior segment $(\mathrm{L})$ & 0 & 0 & 25 & 43.1 & $<0.001^{\#}$ \\
\hline Apical segment (L) & 0 & 0 & 17 & 29.31 & $<0.001^{\#}$ \\
\hline Posterior segment (L) & 0 & 0 & 23 & 39.66 & $<0.001^{\#}$ \\
\hline Superior lingual segments $(\llcorner)$ & 12 & 14.29 & 31 & 53.44 & $<0.001^{\#}$ \\
\hline Inferior lingual segments $(\mathrm{L})$ & 12 & 14.29 & 32 & 55.17 & $<0.001^{\#}$ \\
\hline Superior segments $(\mathrm{L})$ & 8 & 9.52 & 29 & 50 & $<0.001^{\#}$ \\
\hline Anterior basal $(L)$ & 12 & 14.29 & 32 & 55.17 & $<0.001^{\#}$ \\
\hline Medial basal $(\mathrm{L})$ & 10 & 11.9 & 30 & 51.72 & $<0.001^{\#}$ \\
\hline Lateral basal $(\llcorner)$ & 10 & 11.9 & 35 & 60.34 & $<0.001^{\#}$ \\
\hline Posterior basal (L) & 8 & 9.52 & 39 & 67.24 & $<0.001^{\#}$ \\
\hline Anterior segment (R) & 2 & 2.38 & 23 & 39.66 & $<0.001^{\#}$ \\
\hline Apical segment (R) & 2 & 2.38 & 16 & 27.59 & $<0.001^{\#}$ \\
\hline Posterior segment (R) & 4 & 4.76 & 25 & 43.1 & $<0.001^{\#}$ \\
\hline Medial (R) & 8 & 9.52 & 32 & 55.17 & $<0.001^{\#}$ \\
\hline Lateral (R) & 10 & 11.9 & 34 & 58.62 & $<0.001^{\#}$ \\
\hline Superior (R) & 4 & 4.76 & 30 & 51.72 & $<0.001^{\#}$ \\
\hline Anterior basal (R) & 16 & 19.05 & 38 & 65.51 & $<0.001^{\#}$ \\
\hline Medial basal (R) & 22 & 26.19 & 37 & 63.79 & $<0.001^{\#}$ \\
\hline Lateral basal (R) & 24 & 28.57 & 37 & 63.79 & $0.001^{\#}$ \\
\hline Posterior basal (R) & 26 & 30.95 & 32 & 55.17 & $0.016^{\#}$ \\
\hline
\end{tabular}

${ }^{\#}$ Chi-square test, $P$ considered significant if $P<0.05$

Continuous data represented as mean and standard deviation (SD), and categorical data as number and percentage (\%) 


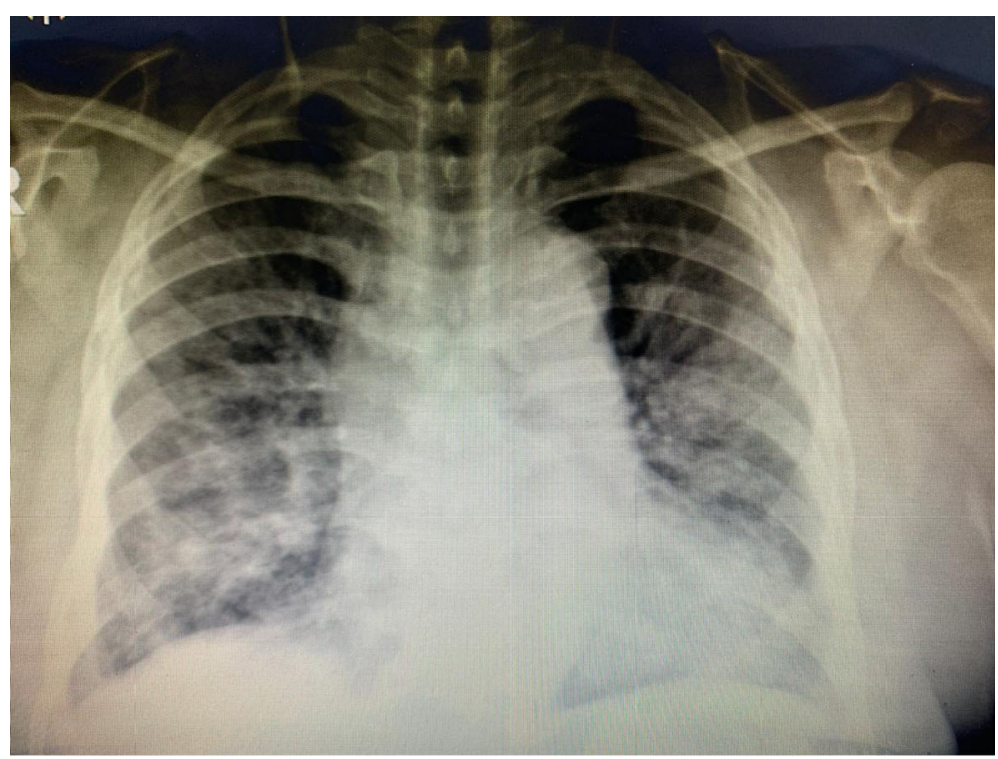

a- GGO with basal consolidation on left side.

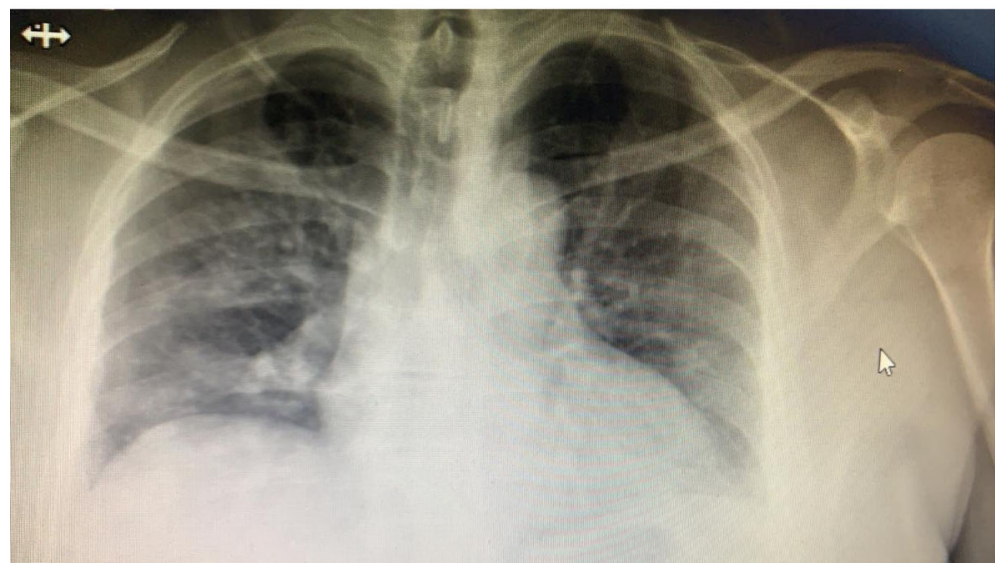

b- Showed perihilar reticulation with RT sided ground glass haziness.

Fig. 1 X-ray of COVID-19 cases. a GGO with basal consolidation on the left side. b Perihilar reticulation with RT-sided ground glass haziness

\section{Statistical analysis}

The data were collected in Excel sheet and statistically analyzed using SPSS 22.0 for windows (SPSS Inc., Chicago, IL, USA). Continuous data was represented as mean and standard deviation (SD) and categorical data as number and percentage (\%). The data normality has been checked using Shapiro Wilk test. Independent $t$ test was used to compare between two different means, and chi-square test was used to compare the frequency of two groups or more. The accuracy of CO-RADS and CT-SS in diagnosing severe COVID-19 were assessed using receiver operating characteristic curve (ROC); the assumption was that the area under the curve (AUC) of 0.9 was significant, with a margin of error about 0.05 and 0.1 for type I and II errors, respectively. The minimum total calculated sample size was 70 , and that for severe COVID-19 was about 35 using MedCalc 13 for windows (MedCalc Software bvba, Ostend, Belgium). All tests were two sided; $P$ considered significant if $<$ 0.05 .

\section{Results}

Demographic characteristics of COVID-19 patients

About 142 patients had confirmed PCR for SARS-Cov-2, 84 of them presented by mild to moderate degree of disease severity. The severe COVID-19 cases were older in age and accompanied with multiple comorbidities (DM, HTN, and IHD) than mild/moderate one, $P<0.001$, 0.003 , and 0.01 , respectively (Table 1 ). In the severe disease group, the mean (SD) duration before admission 
was 4.38 (1.61) days, while in the mild/moderate group, the duration was 3.67 (1) days, $P=0.008$ (Table 1).

\section{Clinical and laboratory characteristics of COVID-19 patients}

Considering the presenting symptoms, cough, dyspnea, and diarrhea were significantly associated with severe disease, $P=0.01,<0.001$, and $<0.001$, respectively. Almost all laboratory markers (ESR, CRP, ferritin, $\mathrm{LDH}$, and $\mathrm{CPK}-\mathrm{MB}$ ) were significantly higher in severe disease, as shown in (Table 1), $P<0.001$ for all, while the lymphocyte \% was significantly lower (19.9\% mean as opposed to 27\%), $P<0.001$. Moreover, the positive D-dimmer was present in $58.62 \%$ of severe case, $P<0.001$.

The CO-RAD score was significantly higher in severe case than in mild/moderate one; thus, the mean CORAD was 5 as opposed to 2 in other groups, $P<0.001$.

\section{Radiological characteristics of COVID-19 patients}

Unilateral X-ray abnormality was significantly characterizing the mild/moderate disease, while almost all severe form had bilateral lesion, $P<0.001$ (Table 2). As shown in Fig. 1a, bilateral peribronchial cuffing was reported, while Fig. 1b shows perihilar reticulation and haziness in RT lung base. The common features in CT chest were ground glass opacity with and without pneumonic consolidation as shown in Fig. 2.

The total CT-SS score was significantly higher in severe disease as well as the score of left and right side; hence, the mean (SD) were 10 (7), 5 (4), and 5(4) respectively, as opposed to 2 (2), 1 (1), and 1(1), respectively, $P<0.001$ for all (Fig. 3 ).

\section{Prognosis of COVID-19 patients}

About 2/3 of severe cases were admitted in ICU (70.69\%) and $1 / 3$ need MV support and developed ARDS (29.31

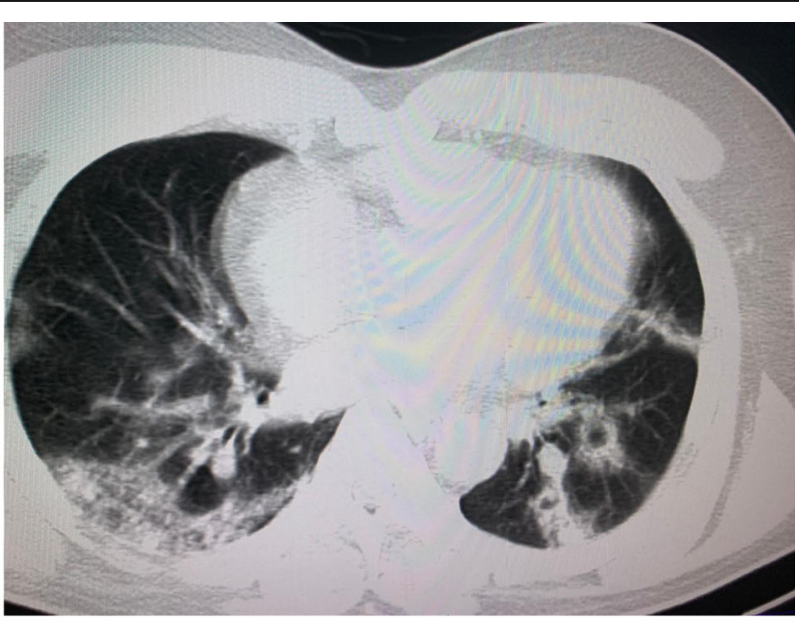

C- Showed pneumonic consolidation on RT lung base

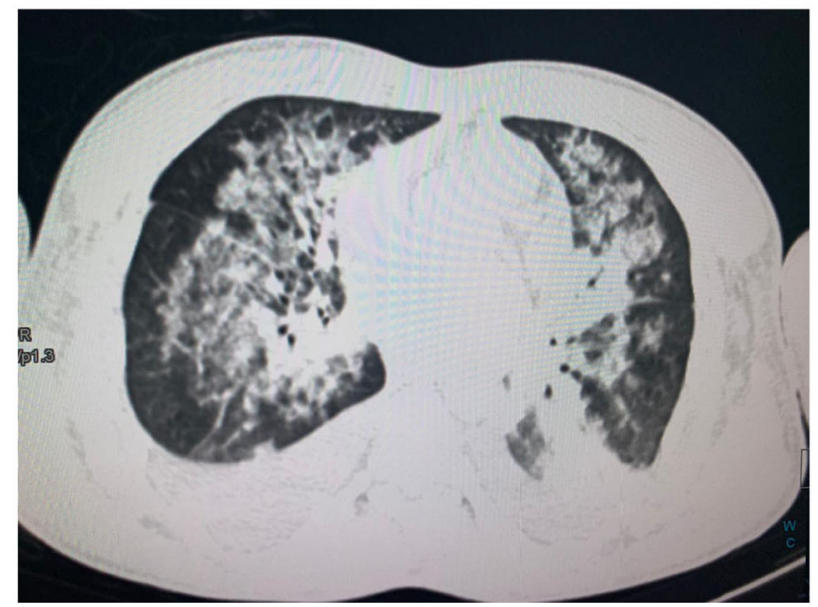

d- Showed crazy paving pattern

b- Showed GGO with pneumonic consolidation on RT lung base

Fig. 2 HRCT features of COVID-19 disease. a Ground glass opacity (GGO). b GGO with pneumonic consolidation on RT lung base. c Pneumonic consolidation on RT lung base. d Crazy paving pattern 


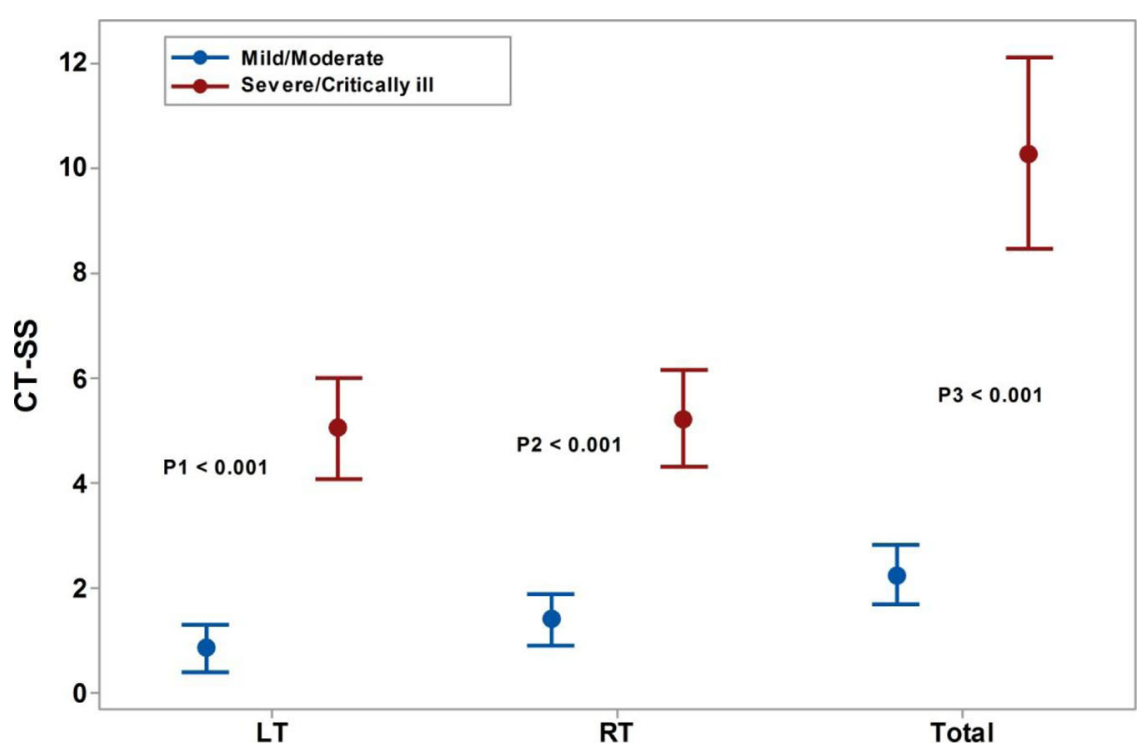

LT: left, RT: right, CT-SS: CT severity score, the test of significant: independent t-

test, $\mathrm{P}$ considered significant if $<0.05$

Fig. 3 CT-SS score in different COVID-19 disease severity: LT, left; RT, right; CT-SS, CT severity score; the test of significance: independent $t$ test, $P$ considered significant if $<0.05$

and $37.39 \%$, respectively). The conversion time (days) to negative swab and length of stay (LOS) in hospital were longer in severe cases than in mild/moderate cases, $P<$ 0.001 for both (Table 3). Mortality was reported only in severe groups, as about $12 \%$ of them died (Table 3 ).

\section{Performance of CT-SS and CO-RAD score in predicting severe COVID-19}

Both CT-SS and CO-RAD score had excellent performance in predicting severe COVID-19; hence, the AUC were 0.89 and 0.97 , respectively, $P<0.001$ for both (Fig. 4). However, in comparing the capability of them, CO-RAD score had the upper hand, as the area difference was -0.078 , and $P=$ 0.002 (Table 4).

The sensitivity, specificity, positive predictive value (PPV), and negative predictive value (NPV) of CT-SS and CO-RAD score were different at different cutoff points, as shown in Table 5, the best cutoff point of CT-SS with higher sensitivity was $>1.5$, while that with higher specificity, the cutoff point was $>7.5$. Furthermore, in CO-RAD score, the specificity for severe COVID-19 was higher (98\%) at cutoff point $>4.5$, with acceptable sensitivity $(88 \%)$.

Table 3 Prognosis of COVID-19 cases

\begin{tabular}{|c|c|c|c|c|c|}
\hline \multirow[t]{2}{*}{ Factors } & \multicolumn{2}{|c|}{ Mild/moderate $(n=84)$} & \multicolumn{2}{|c|}{ Severe/critically ill $(n=58)$} & \multirow[t]{2}{*}{$P$} \\
\hline & N/Mean & $\% / S D$ & N/Mean & $\% / S D$ & \\
\hline ICU need & 0 & 0 & 41 & 70.69 & $<0.001^{\#}$ \\
\hline MV & 0 & 0 & 17 & 29.31 & $<0.001^{\#}$ \\
\hline ARDs & 0 & 0 & 22 & 37.93 & $<0.001^{\#}$ \\
\hline Death & 0 & 0 & 7 & 12.07 & $<0.001^{\#}$ \\
\hline Duration to conversion (days) & 6.5 & 1.19 & 9.38 & 2.7 & $<0.001^{\S}$ \\
\hline LOS (day) & 6.76 & 1.25 & 8.69 & 2.01 & $<0.001^{\S}$ \\
\hline
\end{tabular}

${ }_{\S}$ Independent $t$ test

${ }^{\#}$ Chi-square test, $P$ considered significant if $P<0.05$

Continues data represented as mean and standard deviation (SD), and categorical data as number and percentage (\%) 


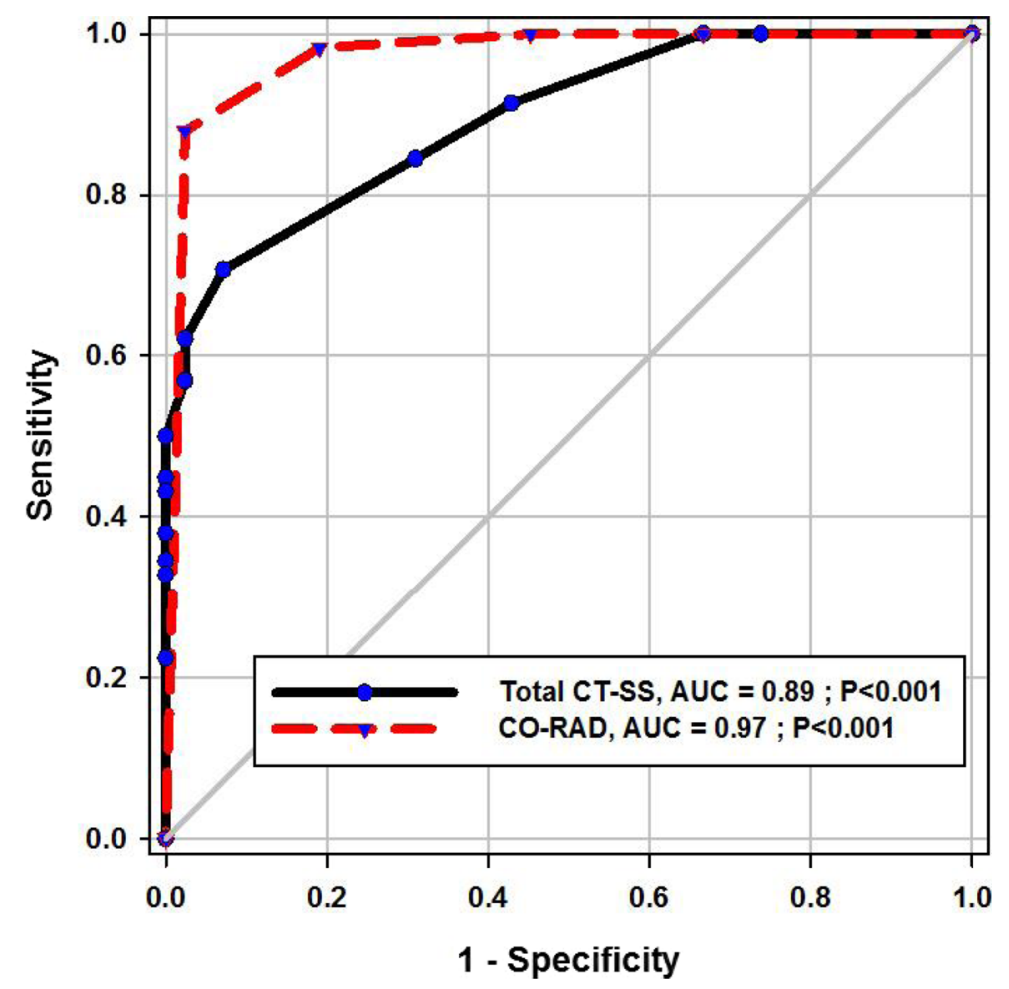

AUC: area under curve, $\mathrm{P}<0.05$ considered significant

Fig. 4 ROC curve of total CT-SS and CO-RADS score: AUC, area under the curve; $P<0.05$ considered significant

\section{Discussion}

The chest CT became an essential diagnostic tool during the COVID-19 outbreak, especially the thin section CT image [16]. Like other viral pneumonia, the features of CT include ground glass opacification, segmental and sub-segmental thickness (crazy paving), consolidation, and interstitial infiltration $[17,18]$. The typical findings in CT of COVID-19 patients were patchy, rounded segmental and sub-segmental ground glass opacification that may be deteriorated to consolidation $[19,20]$. The predominant lesion distribution in the posterior and basal part in our study was closely matched with that of

Table 4 Validity of CT-SS score and CO-RAD score in prediction of severe COVID-19

\begin{tabular}{lll}
\hline Test variables & Total CT-SS & CO-RAD \\
\hline ROC curve area & $\mathbf{0 . 8 9}$ & $\mathbf{0 . 9 7}$ \\
95\% confidence interval & $\mathbf{0 . 8 4 3 8}$ to 0.9460 & $\mathbf{0 . 9 5 0 4}$ to $\mathbf{0 . 9 9 5 5}$ \\
$\quad P$ value & $<\mathbf{0 . 0 0 0 1}$ & $<\mathbf{0 . 0 0 0 1}$ \\
Area difference & $-\mathbf{0 . 0 7 8 0 0}$ & \\
Standard error & $\mathbf{0 . 0 2 9 7 6}$ & \\
95\% confidence interval & $\mathbf{- 0 . 1 2 7 7}$ to $-\mathbf{0 . 0 2 8 3 2}$ \\
$P$ value & $\mathbf{0 . 0 0 2 0 8 9}$
\end{tabular}

$R O C$ Receiver operating characteristics, $P<0.05$ considered significant
Song et al. [21] who found that $82 \%$ of COVID-19 patients had posterior lung involvement, as well as to Yang et al.'s [11], whose results added that the consolidation was significantly associated with disease severity too. Moreover, the data on SARS-Cov-1 and MERS Cov infections signify that posterior segment affection predominance [22, 23].

The role of chest X-ray in our study was limited and less sensitive, particularly in the early stage of the disease, as the abnormality was closely related to severe disease (100\% versus $42.86 \%$ in mild/moderate disease), $P<$ 0.001 . On the other hand, the tiny opacity in any areas of 20 subjective CT locations was denoted and scored. Some authors accounted that the role of X-ray was established in the follow-up stage; therefore, the sensitivity of X-ray was $59 \%[24,25]$.

In our study, the total CT-SS was significantly higher in severe COVID-19 disease than in the mild/moderate group; thus, the mean (SD) were 10 (7) as opposed to 2 (2), which was in agreement with Yang et al.'s study [11]. Additionally, at 2.5 point, the sensitivity was $91 \%$ that gave NPV about 97\%; also, by increasing the threshold point to 7.5 or more, the specificity increased up to $100 \%$ with NPV about $91 \%$. There was a discrepancy between our cutoff value and that of Yang et al.'s study 
Table 5 Performance of CT-SS and CO-RAD score in predicting severe COVID-19

\begin{tabular}{|c|c|c|c|c|c|c|}
\hline Test & Sensitivity & $95 \% \mathrm{Cl}$ & Specificity & $95 \% \mathrm{Cl}$ & PPV & NPV \\
\hline \multicolumn{7}{|c|}{ Total CT-SS } \\
\hline \multicolumn{7}{|c|}{ Cutoff > } \\
\hline 1.5 & $100 \%$ & 0.9384 to 1.000 & $33 \%$ & 0.2342 to 0.4446 & $25 \%$ & $100 \%$ \\
\hline 2.5 & $91 \%$ & 0.8102 to 0.9714 & $57 \%$ & 0.4588 to 0.6789 & $32 \%$ & $97 \%$ \\
\hline 7.5 & $50 \%$ & 0.3658 to 0.6342 & $100 \%$ & 0.9570 to 1.000 & $100 \%$ & $90 \%$ \\
\hline \multicolumn{7}{|l|}{ CO-RAD } \\
\hline \multicolumn{7}{|c|}{ Cutoff $>$} \\
\hline 2.5 & $100 \%$ & 0.9384 to 1.000 & $55 \%$ & 0.4352 to 0.6566 & $33 \%$ & $100 \%$ \\
\hline 3.5 & $98 \%$ & 0.9076 to 0.9996 & $81 \%$ & 0.7092 to 0.8870 & $53 \%$ & $100 \%$ \\
\hline 4.5 & $88 \%$ & 0.7670 to 0.9501 & $98 \%$ & 0.9166 to 0.9971 & $89 \%$ & $97 \%$ \\
\hline
\end{tabular}

$\mathrm{Cl}$ confidence interval, $P P V$ positive predictive value, NPV negative predictive value

[11], in which the chosen value was higher than our value of 19.5 , giving sensitivity and specificity about $83.3 \%$ and $94 \%$, respectively. It may be due to his small number of severe COVID-19 cases than that of ours (18 versus 58) even with equal performance of CT-SS in discriminating severe COVID-19 disease (AUC $=89 \%$ ).

In a study conducted by Bellini et al. [26] to validate CO-RADS accuracy in diagnosing COVID-19 cases, the threshold value of 4 and more provided reasonable sensitivity and specificity of $61 \%$ and $81 \%$, respectively, with AUC about $72 \%$. While in our study, the same cutoff point has been used to predict severe COVID-19 cases and offered sensitivity and specificity about $88 \%$ and $98 \%$, respectively, with AUC about $97 \%$. Our results were quite close to those of Prokop et al.'s [11], who found the accuracy of CORADS was $91 \%$. The difference in the results between Bellini and Prokop could be related to observer experience; thus, the latter involved an expert radiologist with at least 20 years of expertise in CT reading. So, the learning curve of the radiologist may be considered as a factor that implied the outcome. The results of the current work show that among the CT-based score systems of perceptive COVID-19 disease particularly in the severe stage, the CORADS score had significant insight over CT-SS, hence the AUC difference; 95\% CI was (- 0.07; 0.1277 to -0.02832$), P=0.002$. Furthermore, our study was the first of its kind to provide comparative analysis between two different radiological-based score systems (CT-SS and CO-RADS), as well as to use the aforementioned score in discriminating severe COVID-19 disease, not only positive RT-PCR based COVID-19. Both scores had excellent accuracy, $89 \%$ for CT-SS and $97 \%$ for CO-RADS. In spite of that, this retrospective study had some limitation: first, being a one-center study with limited numbers of cases and, second, the first CT of patients at presentation time was used for analysis, while the rest of follow-up CT and progressive data, which may be implicated with the degree of lesions, had been overlooked. Consequently, another complementary study was needed to find the variability between the initial CT presentations and the follow-up one.

\section{Conclusion}

In conclusion, the present work highlights the important role of CT chest and its score base; CT-SS score of less than 7.5 and CO-RADS less than 4.5 could rule out severe COVID-19 disease by NPV about $90 \%$ and $97 \%$, respectively. Moreover, CT score in addition to patient's clinical parameters empowers the triage options especially during the peak of the pandemic wave.

\section{Abbreviations}

ABG: Arterial blood gas; ALT: Alanine aminotransferase; ARDS: Acute respiratory distress syndrome; AST: Aspartate transaminase; AUC: Area under the curve; $\mathrm{CBC}$ : Complete blood count; $\mathrm{Cl}$ : Confidence interval; $\mathrm{CO}-$ RADS: COVID-19 Reporting and Data System; COPD: Chronic obstructive pulmonary disease; COVID-19: Corona virus disease 19; CPK-MB: Creatine phosphokinase myocardial band; CRP: C-reactive protein; CT: Computed tomography; CT-SS: Severity scoring system; DM: Diabetes mellitus; ESR: Erythrocyte sedimentation rate; FiO2: Fraction of inspired oxygen; GGO: Ground glass opacity; HB: Hemoglobin; HRCT: High-resolution computed tomography; HTN: Hypertension; ICU: Intensive care unit; IHD: Ischemic heart disease; LDH: Lactate dehydrogenase; LOS: Length of stay; MERS Cov: Middle East respiratory syndrome-related corona virus; MPR: Multiplanar reformatting technique; MPV: Mean platelet volume; MV: Mechanical ventilation; NPV: Negative predictive value; PaO2: Partial pressure of arterial blood oxygen; PLT: Platelet count; PPV: Positive predictive value; ROC: Receiver operating characteristic curve; RT RT-PCT: Real-time reverse transcriptase polymerase chain reaction; RT-PCR: Real-time polymerase chain reaction; SARS-Cov-2: Severe respiratory distress syndrome corona virus 2; SD: Standard deviation; TLC: Total leucocytes count; WHO: World health organization

\section{Acknowledgements}

Not applicable

Authors' contributions

$\mathrm{ZN}, \mathrm{BM}$, and LM all shared in the conception, design of the work, and acquisition, analysis, and interpretation of the data. The authors read and approved the final manuscript. 
Funding

No financial support or sponsorship.

\section{Availability of data and materials}

The database used and analyzed during the current study are available from the corresponding author on reasonable request

\section{Ethics approval and consent to participate}

The study was approved by Ethics Committee of Saudi National Hospital. A written informed consent was obtained from all participants.

\section{Consent for publication}

Not applicable

\section{Competing interests}

The authors declare no competing interests

\section{Author details}

${ }^{1}$ Chest Department, Faculty of Medicine, Zagazig University, Zagazig, Egypt ${ }^{2}$ Radiology Department, Faculty of Medicine, Zagazig University, Zagazig Egypt

Received: 27 November 2020 Accepted: 15 February 2021

Published online: 27 February 2021

\section{References}

1. World Health Organization website. Naming the coronavirus disease (COVID-2019) and the virus that causes it. www.who.int/emergencies/disea ses/novel-coronavirus2019/technical-guidance/naming-the-coronavirusdisease-(covid-2019)-andthe-virus-that-causes-it. Published 2020. Accessed 26 Feb 2020

2. World Health Organization website. Summary of probable SARS cases with onset of illness from 1 November 2002 to 31 July 2003 (based on data as of December 31, 2003). www.who.int/csr/sars/country/table2004_04 21/en/. Accessed 19 Jan 2020

3. Huang C, Wang Y, Li X et al (2020) Clinical features of patients infected with 2019 novel coronavirus in Wuhan, China. Lancet 395:497-506

4. Zhu N, Zhang DY, Wang WL et al (2019) A novel coronavirus from patients with pneumonia in China, 2019. N Engl Med 382:727-733

5. Li Y, Yao L, Li J, et al. Stability issues of RT-PCR testing of SARS-CoV-2 for hospitalized patients clinically diagnosed with COVID-19. J Med. Virol 2020; 92(7):903-8.

6. Ai T, Yang Z, Hou H, et al. Correlation of chest $C T$ and RT-PCR testing in coronavirus disease 2019 (COVID-19) in China: a report of 1014 cases. Radiology. 2020:296:E32-E40

7. Wang W, Xu Y, Gao R, et al. Detection of SARS-CoV-2 in different types of clinical specimens. JAMA. 2020;323:1843-4

8. Zou L, Ruan F, Huang M et al (2020) SARS-CoV-2 viral load in upper respiratory specimens of infected patients. N Engl J Med 382(12):1177-1179

9. Corman VM, Landt O, Kaiser M et al (2020) Detection of 2019 novel coronavirus (2019- nCoV) by real-time RT-PCR. Euro Surveill 25(3)

10. Inui S, Fujikawa A, JitsuMet al (2020) Chest $C T$ findings in cases from the cruise ship "diamond princess" with coronavirus disease 2019 (COVID-19). Radiol Cardiothorac Imaging. 2020;2(2):e200110.

11. Yang R, Li X, Liu H, Zhen Y, Zhang X, Xiong Q, Luo Y, Gao C, Zeng W (2020) Chest CT severity score: an imaging tool for assessing severe COVID-19. Radiology: Cardiothoracic Imaging 2(2):e200047

12. Prokop M, Van Everdingen W, Van Rees Vellinga T. CO-RADS: A Categorical CT Assessment Scheme for Patients Suspected of Having COVID-19 Definition and Evaluation. Radiology. 2020;296(2):E97-E104

13. Wu Z, McGoogan JM (2020) Characteristics of and important lessons from the coronavirus disease 2019 (COVID-19) outbreak in China: summary of a report of 72314 cases from the Chinese Center for Disease Control and Prevention. JAMA 323:1239-1242. https://doi.org/10.1001/jama.2020.2648

14. Chang YC, Yu CJ, Chang SC et al (2005) Pulmonary sequelae in convalescent patients after severe acute respiratory syndrome: evaluation with thin-section CT. Radiology 236(3):1067-1075

15. Hansell DM, Bankier AA, MacMahon H, McLoud TC, Müller NL, Remy J (2008) Fleischner society: glossary of terms for thoracic imaging. Radiology 246 697-722
16. Chinese Society of Radiology (2020) Radiological diagnosis of new coronavirus infected pneumonitis: expert recommendation from the Chinese Society of Radiology (first edition). Chin J Radiol 54(00):E001-E001. https://doi.org/10.3760/cma.j.issn.1005-1201.2020.0001

17. Koo HJ, Lim S, Choe J et al (2018) Radiographic and CT features of viral pneumonia. Radiographics 38(3):719-739

18. Franquet T (2011) Imaging of pulmonary viral pneumonia. Radiology 260(1): 18-39

19. Liu P, Tan XZ (2020) 2019 novel coronavirus (2019-nCoV) pneumonia. Radiology:200257. https://doi.org/10.1148/radiol.2020200257

20. Chung M, Bernheim A, Mei X,et al. CT Imaging Features of 2019 Novel Coronavirus (2019-nCoV). Radiology. 2020;295:202-7

21. Song F, Shi N, Shan F, et al. Emerging Coronavirus 2019-nCoV Pneumonia. Radiology. 2020;295:210-7

22. Wong KT, Antonio GE, Hui DS et al (2003) Severe acute respiratory syndrome: radiographic appearances and pattern of progression in 138 patients. Radiology 228(2):401-406

23. Ajlan AM, Ahyad RA, Jamjoom LG et al (2014) Middle East respiratory syndrome coronavirus (MERS-CoV) infection: chest CT findings. AJR Am J Roentgenol 203(4):782-787

24. Guan WJ, Ni ZY, Hu Y, et al. Clinical Character istics of Coronavirus Disease 2019 in China. N Engl J Med. 2020;382:1708-20.

25. Wang Y, Dong C, Hu Y, et al. Temporal Changes of CT Findings in 90 Patients with COVID-19 Pneumonia: A Longitudinal Study. Radiology. 2020; 296(2):E55-E64

26. Bellini D, Panvini N, Rengo M, Vicini S, Lichtner M, Tieghi T, Ippoliti D, Giulio F, Orlando E, lozzino M, Ciolfi MG. Diagnostic accuracy and interobserver variability of CO-RADS in patients with suspected coronavirus disease-2019: a multireader validation study. European radiology. 2020;23:1-9.

\section{Publisher's Note}

Springer Nature remains neutral with regard to jurisdictional claims in published maps and institutional affiliations.

\section{Submit your manuscript to a SpringerOpen ${ }^{\circ}$ journal and benefit from:}

- Convenient online submission

- Rigorous peer review

- Open access: articles freely available online

- High visibility within the field

- Retaining the copyright to your article

Submit your next manuscript at $>$ springeropen.com 